\title{
HOSPITAL AS A SMOKE-FREE WORKPLACE
}

\author{
Lenka Štěpánková1, Lenka Kostelecká ${ }^{1,2}$, Veronika Stejskalová2, Milena Kalvachová2, Eva Králíková1,3 \\ ${ }^{1}$ Centre for Tobacco Dependence, Third Medical Department, Department of Endocrinology and Metabolism, First Faculty of Medicine, \\ Charles University and General University Hospital in Prague, Prague, Czech Republic \\ ${ }^{2}$ Ministry of Health of the Czech Republic, Prague, Czech Republic \\ ${ }^{3}$ Institute of Hygiene and Epidemiology, First Faculty of Medicine, Charles University and General University Hospital in Prague, Prague, Czech Republic
}

\section{SUMMARY}

Objectives: The primary aim of a hospital is to promote/improve and restore health, thus smoking, whether in its passive or active form, should be banned in all hospital premises for the benefit of employees and patients alike. The Global Network for Tobacco Free Healthcare Services (GNTH) is an international non-profit association formed in 1999. The GNTH's mission is to implement tobacco-free policies to create a healthy workplace and patients' environment; help physicians, nurses and other healthcare workers to stop smoking; and educate all caregivers about tobacco dependence treatment and support them in providing smoking cessation interventions.

Methods: Implementation standards and a system of their self-audit for all participating hospitals were developed by the GNTH. We describe both the international and Czech networks, recommended methods for programme implementation and results of self-audit questionnaires completed by Czech participating hospitals.

Results: Worldwide, there are 19 national networks with 1,672 members including 56 gold forum members. To date, the largest network has been formed in France ( 670 members), followed by Spain (580) and Taiwan (209). After the first Czech institution (Prague-based General University Hospital) joined GNTH in 2010, the Czech Republic established its national network in 2017 currently comprising 10 members, of this number 1 gold, 3 silver and 6 bronze national certification level members. The main barriers to better outcomes in the Czech Republic include smoking on outdoor hospital grounds, lack of pharmacotherapy reimbursement and time, and inadequate staff education in the field of tobacco dependence treatment.

Conclusions: The Global Network's mission is to advocate, recruit and enable healthcare services and professionals to implement and sustain effective tobacco management and cessation policies in accordance with the WHO Framework Convention on Tobacco Control (FCTC). A systematic approach supports the quality of care and treatment outcomes for patients as well as healthy workplace conditions for the staff.

Key words: tobacco control, hospital, education, health promotion, tobacco-free health care

Address for correspondence: L. Štěpánková, Centre for Tobacco Dependence, Third Medical Department, Department of Endocrinology and Metabolism, First Faculty of Medicine, Charles University and General University Hospital in Prague, Karlovo náměstí 32, 12800 Prague 2, Czech Republic. E-mail: Lenka.Stepankova@vfn.cz

https://doi.org/10.21101/cejph.a6172

\section{INTRODUCTION}

The primary aim of a hospital is to promote/improve health, thus smoking, whether in its passive or active form, should be banned on all hospital premises for the benefit of employees and patients alike.

Yet the sad fact is that a significant proportion of patients and hospital staff still smoke. In the latest survey carried out in 2010, $17 \%$ of physicians and $41 \%$ of nurses smoked in one of the respondent hospitals (1). While no reliable information on the smoking status of patients during hospitalization is available, the prevalence of smoking among those aged 15+ in the Czech Republic in 2018 was $28.5 \%$ (21.1\% daily and $7.4 \%$ occasional smokers) (2).

While smoking by healthcare workers has many adverse effects on their individual health, it may also reduce their motivation to provide smoking cessation interventions to their patients. Being a non-smoking role model is also a part of their professional role and responsibility (3).

There is evidence that tobacco control measures in hospitals as well as in other workplaces (especially smoking cessation programmes, both for individuals and groups and pharmacological treatment to overcome nicotine addiction) could decrease the prevalence of smoking among healthcare personnel and help to achieve a healthy work environment (4-7). Likewise, there is evidence of the efficacy of smoking cessation interventions for hospitalized patients (8).

The Global Network for Tobacco Free Healthcare Services (GNTH) is an international organisation formed in 1999. Its mission is to implement tobacco-free policies in order to create a healthy workplace and patient environment; help physicians, nurses and other medical healthcare workers stop smoking; and educate all caregivers about tobacco dependence treatment and support them in providing smoking cessation interventions. The organization has adopted 8 standards (S) of implementation: S1: Governance and Commitment, S2: Communication, S3: Education and Training, S4: Identification, Diagnosis and Smoking Cessation Support, S5: Tobacco-free Environment, S6: Healthy Workplace, S7: Community Engagement and S8: Monitoring and Evaluation. The objectives of each of these standards are summarized in Table 1. 
Table 1. Global Network for Tobacco Free Healthcare Services (GNTH) for the implementation of tobacco control policies in healthcare settings and their objectives (9)

\begin{tabular}{|l|l|l|}
\hline Standard 1 & Governance and Commitment & $\begin{array}{l}\text { The healthcare organization has clear and strong leadership to systematically implement } \\
\text { a tobacco-free policy }\end{array}$ \\
\hline Standard 2 & Communication & $\begin{array}{l}\text { The healthcare organization has a comprehensive communication strategy to support awareness } \\
\text { and implementation of the tobacco-free policy and tobacco cessation services. }\end{array}$ \\
\hline Standard 3 & Education and Training & $\begin{array}{l}\text { The healthcare organization ensures appropriate education and training for clinical and } \\
\text { non-clinical staff. }\end{array}$ \\
\hline Standard 4 & $\begin{array}{l}\text { Identification, Diagnosis and Tobacco } \\
\text { Cessation Support }\end{array}$ & $\begin{array}{l}\text { The healthcare organization identifies all tobacco users and provides appropriate care in line with } \\
\text { international best practice and national standards. }\end{array}$ \\
\hline Standard 5 & Tobacco-free Environment & The healthcare organization has strategies in place to achieve a tobacco-free campus. \\
\hline Standard 6 & Healthy Workplace & $\begin{array}{l}\text { The healthcare organization has human resource management policies and support systems that } \\
\text { protect and promote the health of all who work in the organisation. }\end{array}$ \\
\hline Standard 7 & Community Engagement & $\begin{array}{l}\text { The healthcare organization contributes to and promotes tobacco control/prevention in the local } \\
\text { community according to the WHO FCTC and/or national public health strategy. }\end{array}$ \\
\hline Standard 8 & Monitoring and Evaluation & $\begin{array}{l}\text { The healthcare organization monitors and evaluates the implementation of all the GNTH-Global } \\
\text { standards at regular intervals. }\end{array}$ \\
\hline
\end{tabular}

WHO - World Health Organization

FCTC - Framework Convention on Tobacco Control

The World Health Organization's (WHO) Framework Convention on Tobacco Control (FCTC, referred to as "the Convention" hereinafter) is the first legally binding treaty negotiated under the auspices of the WHO. It is an evidence-based treaty reaffirming the right of all people to the highest standard of health and it has been developed in response to the globalization of the tobacco epidemic, formulating at least the basic rules for tobacco control. The convention articles concerning price and tax measures to reduce the demand for tobacco and non-price measures include: protection from exposure to tobacco smoke; regulation of the contents of tobacco products; regulation of tobacco product disclosures; packaging and labelling of tobacco products; education, communication, training and public awareness; tobacco advertising, promotion and sponsorship; and demand reduction measures concerning tobacco dependence and cessation (10). The Czech Republic became a Party to the Convention after its ratification in 2012.

\section{MATERIALS AND METHODS}

We describe both the international and Czech GNTH networks and recommend methods for programme implementation. The main activities within the Czech network and the results of the self-audit questionnaire of participating Czech hospitals are listed below.

The Global Network for Tobacco-free Hospitals developed implementation standards and a system of their self-audit for all participating hospitals. To complete a survey of GNTH standard implementation in the Czech Republic is recommended annually or, possibly, each second year. Information about the process and a template of the self-audit questionnaire/tool are available in the Czech language at the websites of the Czech Ministry of Health (11) and also at the websites of the Czech Society for the Treatment of Tobacco Dependence (12). The GNTH website offers the most important information and the self-audit tool available in 19 different languages (13). The self-audit tool contains 48 questions with a maximum of 144 points to achieve, with the score of each standard and sub-standard based on the level of implementation from 0 (no implementation) to 3 (full implementation). A minimum of 27 points is needed for bronze national certification level membership, 108 points for the silver certification, and 126 or more points and an international audit are required for the gold forum level.

The results of the last audit undertaken in each of 10 Czech participating hospitals with a deadline in February 2020 are shown in Table 2. To identify the main barriers and challenges within the Czech network, we used data from the self-audit tools, data about the activities presented during three annual conferences called Development of Activities to Promote Health and Quality of Care in Healthcare Facilities in the Czech Republic in the 2017-2019 Period (14) and the implementation strategy of participating hospitals, if available.

\section{RESULTS}

Worldwide, there are 19 national networks with 1,672 members including 56 gold forum members. To date, the largest network has been formed in France (670 members), followed by Spain (580) and Taiwan (209). The first Czech organization (the Prague-based General University Hospital) joined GNTH in 2010, with the Czech Republic forming its national network (National Network of Tobacco-free Hospital and Healthcare Facilities) currently comprising 10 members in 2017.

The only Czech hospital currently meeting the requirements for the gold national certification level is the Prague-based General Military Hospital. The reason for not being a member of the gold forum is that it has not undertaken an international audit yet. There are 3 silver and 6 bronze national certification level members (Table 2).

In all GNTH member hospitals, the Centres for Tobacco Dependence Treatment provide evidence-based treatment, 
Table 2. List of Global Network for Tobacco Free Healthcare Services (GNTH) members in the Czech Republic and levels of their membership

\begin{tabular}{|l|l|l|l|}
\hline GNTH Hospital & Latest SAT (self-audit tool) & Points Awarded & National Certification Level \\
\hline Královské Vinohrady University Hospital & 2019 & 111 & Silver \\
\hline Olomouc University Hospital & 2019 & 85 & Bronze \\
\hline Associated Medical Facility in Krnov* & 2018 & 105 & Bronze \\
\hline Hradec Králové University Hospital & 2019 & 61 & Bronze \\
\hline General University Hospital in Prague & 2019 & 112 & Silver \\
\hline Motol University Hospital & 2019 & 101 & Bronze \\
\hline Central Military Hospital - Military University Hospital Prague & 2020 & 127 & Gold \\
\hline Jihlava Hospital* & 2019 & 118 & Silver \\
\hline Havlí̌kův Brod Hospital & Pending & $\neq$ & Bronze at min. \\
\hline Pelhřimov Hospital & Pending & $\neq$ & Bronze at min. \\
\hline
\end{tabular}

*State-funded organization

i.e., psycho-behavioural interventions and pharmacotherapy to overcome tobacco dependence according to the current treatment guidelines. The Reference Centre for the Czech Republic in the Prague-based General University Hospital is open to smokers among patients and hospital staff as well as to all smokers motivated to break the habit. While this centre offers its services throughout its opening hours, in other hospitals such centres are opened for at least several hours a week. A list of all centres in the Czech Republic (both at tobacco-free hospitals and other hospitals) is available at the website of the Czech Society for the Treatment of Tobacco Dependence*. While all centres provide outpatient therapy, only some of them offer bedside consultations. This is partly due to the fact that medical tobacco dependence interventions are reimbursed exclusively for outpatients and, similarly, pharmacotherapy to reduce withdrawal symptoms is only partially reimbursed for outpatients but not for hospitalized patients.

Another key activity is to record the smoking status and smoking cessation interventions in patients' medical records. It is critical to educate health professionals as broadly as possible in providing brief interventions in smoking cessation. However, seminars for physicians and nurses are held in only some hospitals and have insufficient capacity, although mandatory implementation of brief interventions is enshrined in Czech law. E-learning courses appear to be one of the good yet inexpensive options.

The cornerstone of the process is communication between all hospital care participants (management, healthcare professionals and patients). Among GNTH members, awareness of smoking bans, no-smoking graphic signs, the level of awareness of the non-smoking policy among new and long-term workers has improved, and the number of smoking places has decreased. Smoking on hospital premises is prohibited by law in the Czech Republic with the exception of psychiatric and detoxification departments. Nevertheless, some of these departments of the GTNH network have introduced a total ban on indoor smoking (Psychiatry Department of the Central Military Hospital, Clinic of Addictology of the General University Hospital) and provide hospitalized patients with nicotine replacement therapy (NRT)

* https://www.slzt.cz from their own resources. Some facilities partially reimburse pharmacotherapy for the treatment of tobacco dependence to their employees.

\section{Public Events}

All participating hospitals have declared cooperation with their regional organizations and at least one (1-4) public events focusing on the harmfulness of smoking and treatment options. Most of these events take place as part of the International NonSmoking Day or World No Tobacco Day and include exhaled CO measurement and treatment offers.

The main platform for discussions and information sharing of GNTH coordinators, responsible members of hospital management and authorized employees of the Ministry of Health is currently a newly established working group (Working Group for the Implementation of International Health Promotion Principles in Quality Management in Healthcare Services), with its first meeting held in January 2020. The professional events suitable for acquiring and sharing new information to be held in the Czech Republic in the near future include a conference called the Development of Activities to Promote Health and Quality of Care in Healthcare Facilities, the regular Conference on Tobacco Dependence Treatment for the centre's healthcare workers and the 21 st edition of the Conference on Tobacco and Health for all healthcare workers interested. As to related international events, Czech GNTH representatives present at the Health Promoting Hospitals and Health Services (HPH) conference on a regular basis with the GNTH conference and Society for Research on Nicotine and Tobacco conferences; subsequent dissemination of information from international conferences into the Czech environment helps to effectively implement the programme.

On the contrary, the main barriers for better outcomes in the Czech Republic often include smoking on outdoor hospital grounds, low pharmacotherapy reimbursement (in fact none during hospitalization), and inadequate time and staff education in the tobacco dependence treatment field. Furthermore, 
there is still room for improvement in communication strategies and feedback between management, healthcare workers, and patients.

\section{DISCUSSION}

The implementation of the Tobacco-free Hospitals project contributes to the Convention in the Czech Republic, specifically to the implementation of Article 8 of the Convention concerning protection against exposure to tobacco smoke. It includes, inter alia, a commitment to promote the adoption and implementation of effective measures providing for protection from exposure to tobacco smoke in indoor workplaces, indoor public places, and in other public places as appropriate (10). In the Czech Republic, this provision in relation to health care facilities is reflected in Act No. 65/2017 Coll., on the Protection of Health from the Harmful Effects of Addictive Substances.

Activities related to the provision of brief interventions and intensive tobacco dependence treatment contribute to the implementation of Article 14 of the Convention. This Article focuses on demand reduction measures concerning tobacco dependence and smoking cessation. According to Article 14, each Party shall endeavour to design and implement effective programmes aimed at promoting the cessation of tobacco use in different types of locations, such as healthcare facilities and workplaces etc. Establishing programmes for diagnosis, counselling, prevention, and treatment of tobacco dependence in healthcare facilities and rehabilitation centres is a further example of provisions under Article 14 (10) with relevance to the Tobacco-free Hospitals project.

Promotion of public and staff awareness of tobacco prevention and other related issues within the Tobacco-free Hospitals project is in line with Article 12 of the Convention on education, communication, training, and public awareness (10).

In addition, there are guidelines for the implementation of the above Articles of the Convention as adopted by the Conference of the Parties to the Convention (COP). The guidelines including definitions, guiding principles, detailed recommendations, etc., are intended to assist parties in fulfilling their obligations under the Convention, including those related to creation of a non-smoking environment in healthcare facilities (15).

Besides these clear and evidence-based recommendations, many questions remain to be answered such as how to best motivate patients and hospital staff to stop smoking, how to promote the important role of all healthcare providers (physicians, nurses, dentists, midwives, etc.) in smoking cessation, how to support the dissemination of relevant information and encourage other organizations to join the GNTH. And, very importantly, how to ensure related health improvement activities with minimal administrative burden. The answer is international collaboration, sharing of good practice examples within the GTNH, in relevant publications and conferences and joint efforts aimed at empowering the Convention's implementation at the national level. Comprehensive information is available at the GNTH website $^{* *}(16)$ and, in the Czech language at the websites of the Society for Tobacco Dependence Treatment (12) and the Ministry of Health of the Czech Republic (17). These programmes often include further hospital staff education,

** https://www.tobaccofreehealthcare.org stop smoking campaigns for healthcare workers, students and patients, restriction of smoking places, collaboration within the hospital and with local organizations as well as allocation of resources for these activities.

Other options include the inclusion of tobacco control activities of health professionals in the scope of work of professional societies such as the Czech Medical Society of Jan Evangelista Purkyně in the curriculum of medical faculties (both medical and non-medical fields) and in the work of the inter-ministerial group coordinating the Health 2020 programme and other health promoting activities.

\section{CONCLUSIONS}

The Global Network's mission is to advocate, recruit and enable healthcare services and professionals to implement and sustain effective tobacco management and cessation policies in accordance with the WHO Framework Convention on Tobacco Control (FCTC). Much has been done but some barriers still remain. The main barriers for better outcomes in the Czech Republic include smoking on outdoor hospital grounds, low pharmacotherapy reimbursement and inadequate time and staff education in the tobacco dependence treatment field.

A more systematic approach to tobacco control in the Czech Republic would greatly improve the quality of healthcare and patients' treatment outcomes, as well as workplace conditions of the hospital staff.

\section{Acknowledgements}

The study was partially supported by the Charles University project PROGRES Q25/LF1. We thank all members of the Czech national GNTH network for their cooperation.

\section{Conflict of Interests}

None declared

\section{REFERENCES}

1. Štěpánková L. What does it mean „Tobacco Free Hospital“"? Cas Lek Ces. 2017;156(1):24-7. (In Czech.)

2. Csémy L, Dvořáková Z, Fialová A, Kodl M, Skývová M. Tobacco and alcohol use in the Czech Republic 2018 [Internet]. Prague: NIPH; 2019 [cited 2020 Apr 21]. Available from: http://www.szu.cz/uploads/documents/szu/aktual/uzivani tabaku alkoholu cr 2018.pdf. (In Czech.)

3. WHO Tobacco Free Initiative?. The role of health professionals in tobacco control. Geneva: WHO; 2005.

4. Martínez C, Garcia M, Méndez E, Peris M, Fernández E. Barriers and challenges for tobacco control in a smoke-free hospital. Cancer Nurs. 2008;31(2):88-94.

5. Cahill K, Moher M, Lancaster T. Workplace interventions for smoking cessation. Cochrane Database Syst Rev. 2008;(4):CD003440. doi:10.1002/14651858.CD003440.pub3.

6. Cahill K, Lancaster T. Workplace interventions for smoking cessation Cochrane Database Syst Rev. 2014;(2):CD003440. doi:10.1002/14651858. CD003440.pub4.

7. Fishwick D, Carroll C, McGregor M, Drury M, Webster J, Bradshaw L, et al. Smoking cessation in the workplace. Occup Med (Lond). 2013;63(8):526-36.

8. Rigotti NA, Munafo MR, Stead LF. Smoking cessation interventions for hospitalized smokers: a systematic review. Arch Intern Med. 2008;168(18):1950-60.

9. Global Network for Tobacco Free Healthcare Services. The Global Network implementation concept [Internet]. GNTH [cited 2020 Apr 21]. 
Available from: https://www.tobaccofreehealthcare.org/standards/ overview.

10. World Health Organization. WHO Framework Convention on Tobacco Control. Geneva: WHO; 2003.

11. Ministry of Health of the Czech Republic. Global Network Standards self audit template [Internet]. Prague: Ministry of Health of the Czech Republic; 2013 [updated 2019 May 6; cited 2020 Apr 21]. Available from: https://www.mzcr.cz/KvalitaABezpeci/obsah/sebehodnotici-dotaznikgnth_2867_29.html. (In Czech.)

12. Global Network for Tobacco Free Healthcare Services. Self-audit [Internet]. GNTH [cited 2020 Apr 21]. Available from: https://www. tobaccofreehealthcare.org/self-audit/self-audit-overview.

13. Ministry of Health of the Czech Republic. 2nd conference on Development of activities to promote health and quality of care in healthcare facilities [Internet]. Prague: Ministry of Health of the Czech Republic; 2019 [cited 2020 Apr 21]. Available from: https://www.mzcr.cz/ KvalitaABezpeci/dokumenty/2rocnik-konference-rozvoj-aktivit-napodporu-zdravi-a-kvality-pece-ve-zdravotnictvi_16638_29.html. (In Czech.)
14. WHO Framework Convention on Tobacco Control. Guidelines and policy options and recommendations for implementation of the WHO FCTC [Internet]. Geneva: WHO [cited 2020 Apr 21]. Available from: https: //www.who.int/fctc/guidelines/en/

15. Global Network for Tobacco Free Healthcare Services [Internet]. GNTH [cited 2020 Apr 21]. Available from: https://www.tobaccofreehealthcare.org/.

16. Society for Tobacco Dependence Treatment. Tobacco Free Hospitals [Internet]. Prague: Society for Tobacco Dependence Treatment [cited $2020 \mathrm{Apr}$ 21]. Available from: https://www.slzt.cz/nekuracke-nemocnice. (In Czech.)

17. Ministry of Health of the Czech Republic. National Network for Tobacco Free Healthcare Services [Internet]. Prague: Ministry of Health of the Czech Republic; 2017 [updated 2019 Aug 30; cited 2020 Apr 21]. Available from: https://www.mzcr.cz/KvalitaABezpeci/dokumenty/narodnisit-nemocnic-a-zdravotnickych-zarizeni-bez-tabaku-_14320_3778_29. html. (In Czech.)

Received March 10, 2020 Accepted in revised form April 21, 2020 